\title{
Peukert's Generalized Equation Taking into Account the Temperature for Nickel-Cadmium Batteries
}

\author{
Nikolay E. Galushkin*, Nataliya N. Yazvinskaya, Dmitriy N. Galushkin
}

Don State Technical University, Laboratory of electrochemical and hydrogen energy, 147 Shevchenko Street, Town of Shakhty, Rostov Region, Russia, 346500.

*E-mail: galushkinne@mail.ru

doi: $10.20964 / 2019.03 .76$

Received: 2 November 2018 / Accepted: 31 December 2018 / Published: 7 February 2019

In this paper, batteries' temperature influence was analyzed on parameters of Peukert's generalized equation $C=C_{m} /\left(1+\left(i / i_{0}\right)^{n}\right)$. It was proved by experiments that all the parameters $\left(C_{m}, i_{0}\right.$ and $\left.n\right)$ of Peukert's generalized equation depend heavily on battery temperature. So when assessing battery released capacity, it is absolutely necessary to consider battery temperature. Empiric equations have been proposed describing parameter changes $\left(C_{m}, i_{0}\right.$ and $\left.n\right)$ depending on temperature. These equations are correct at any battery temperature values widely used in practice. Thus, experimentally it was proved that the proposed Peukert's generalized equation is correct at any discharge currents and at any battery temperatures, unlike the classical Peukert's equation.

Keywords: Peukert's equation, battery, nickel-cadmium, lithium-ion, temperature

\section{$\underline{\text { FULL TEXT }}$}

(C) 2019 The Authors. Published by ESG (www.electrochemsci.org). This article is an open access article distributed under the terms and conditions of the Creative Commons Attribution license (http://creativecommons.org/licenses/by/4.0/). 